\title{
Inclined Jetting and Splashing in Electric Arc Furnace Steelmaking
}

\author{
Morshed ALAM, ${ }^{1)}$ Gordon IRONS, ${ }^{2)}$ Geoffrey BROOKS, ${ }^{1)}$ Andrea FONTANA ${ }^{3)}$ and Jamal NASER ${ }^{1)}$ \\ 1) Swinburne University of Technology, Hawthorn, Victoria, 3122 Australia. \\ 2) Steel Research Centre, McMaster \\ University, Ontario, Canada. $\quad 3)$ OneSteel, 105-123 Dohertys Road, Laverton North 3026, Victoria, Australia.
}

(Received on March 29, 2011; accepted on May 10, 2011)

\begin{abstract}
In Electric Arc Furnace (EAF) steelmaking, liquid metal splashes on the furnace wall due to the impingement of high speed oxygen jet on molten metal surface. The splashed metal droplets cause wear of furnace wall and loss of production. Optimization of the operating condition (lance angle, lance height and flow rate) may reduce splashing and increase productivity. In the present study, the effect of different operating conditions on the wall splashing rate was investigated. Air was injected on water surface in a small-scale thin slice model at different lance angles, lance heights and flow rates. Splashed liquid in the forward direction was collected and measured in each case. The forward splashing rate was found to increase with the increase of lance angle from the vertical and flow rate. The critical depth of penetration as well as the impact velocity for the onset of splashing was found to decreases with the increase of lance angle from the vertical. The effect of lance angle on the dimensionless Blowing number $\left(N_{B}\right)$, which is a measure of droplet generation rate, was quantified. A new approach has been proposed for modelling the gas jet impinging phenomenon inside the real furnace using room temperature water model.
\end{abstract}

KEY WORDS: Electric Arc Furnace steelmaking; supersonic jet; splashing; turbulent jet.

\section{Introduction}

In Electric Arc Furnace (EAF) steelmaking, scrap metal is melted by using electric arc and oxy-fuel burner inside the furnace. After melting, the molten metal is refined by blowing oxygen supersonically into the bath. Supersonic gas jets are preferred over the subsonic jets because of high dynamic pressure associated with them which results in a higher depth of penetration, increased surface area for reaction because of the generation of more droplets and better mixing. But the high speed gas jets also result in splashing of liquid melt onto the water-cooled panels that may cause premature failure, slag/steel sticking to the lance resulting poor tip life and sidewall refractories premature erosion. ${ }^{1)}$ A significant number of papers ${ }^{2-12}$ have been published on top jetting because of the predominance of Basic Oxygen Furnace (BOF) steelmaking process in which the supersonic oxygen lance is vertical. But limited attention has been paid to the inclined jetting case which is used in EAF steelmaking furnace although the use of EAF route is increasing day by day. ${ }^{13)}$ In 2005, approximately $33.1 \%$ of the world's steel production came from EAF route. ${ }^{13)}$ Collins and Lubanska ${ }^{14)}$ conducted a number of experiments in order to investigate the effect of jet momentum, lance angle and lance height (distance between lance exit and still bath surface) on the depth of penetration. Using dimensional analysis and experimental results, an empirical equation was proposed to calculate the maximum penetration depth. The depth of penetration was found to decrease with the increasing lance angle from vertical. Holden and Hogg reported ${ }^{15)}$ that as the inclination of the lance from vertical became steeper, the depth of the cavity decreases while the length (cavity width along the direction of jet) increases and width (cavity width perpendicular to jet) remain constant. McGee and Irons ${ }^{16)}$ developed a mathematical model to calculate the penetration depth at different lance angle. Peaslee and Robertson ${ }^{1)}$ investigated in detail the mechanism of droplet generation in both top and inclined jetting. In another study, Peaslee and Robertson ${ }^{17)}$ concluded that splashing is reduced by the use of thick, viscous and foamy slags. Li et al. ${ }^{18)}$ observed that the cavities, formed by inclined gas jet, oscillate due to the wave generated by the gas jet and the wave propagates along the base of the cavity. They ${ }^{19)}$ also related the oscillation frequency of the cavity with the formation of different impingement modes (dimpling, splashing and penetrating) reported by Molloy. ${ }^{20)}$ McGee and Irons ${ }^{16)}$ made visual observation of splashing phenomenon due to inclined jetting. They concluded that 40 degree lance angle from vertical produces less splashing from visual observation. There are no direct measurement of splashing rates at different operating conditions (lance angle, flow rate, lance height) available in the current literature. The present experimental study is focused on increasing the understanding of splashing phenomenon at different lance angles, lance heights and flow rates and where possible quantifying these effects.

\section{Experimental Apparatus and Setup}

The experimental study was carried out at Steel Research Centre in McMaster University. The experimental setup, 
used by McGee and Irons, ${ }^{16)}$ was modified for the current study. A one-third scale thin slice water model was used to simulate the ArcelorMittal Dofasco's EAF as shown in Fig 1. The details of the dimensional analysis were discussed by McGee and Irons ${ }^{16)}$ in their paper and therefore, have not been repeated here. The model is $2080 \mathrm{~mm}$ long, $1450 \mathrm{~mm}$ deep and $25 \mathrm{~mm}$ thick. The thin slice model was used to allow measurement of the penetration depth and observe the shape of the cavity more accurately. Thin slice nature of the model introduces some artefacts; the jets penetrate more deeply than a 3D jet because they are constrained in the thin slice dimension; the jet model developed by McGee and Irons accounts for this phenomenon. ${ }^{16)}$ A schematic diagram of the experimental set up is shown in Fig. 2. In this study, water and air were used to simulate steel and oxygen respectively. A slag layer was not considered. A $14 \mathrm{~mm}$ diameter straight lance was used to inject air on the water surface which was connected with a compressed air tank. An in-line flow meter and pressure gauge was used to monitor and control the compressed air before it entered the lance. When the gas jet impinged on liquid surface, it created a depression on the liquid surface and liquid droplets splashed on the wall of the vessel. The depression depth and shape of the cavity was recorded by using Olympus C-7070 wide zoom camera with 7.1 megapixel resolution and $4 x$ optical zoom. The videos were recorded at $15 \mathrm{fps}$ (frames per second). Then by using "Photron Fastcam Viewer" software, the video recording was converted to 15 images per second. The

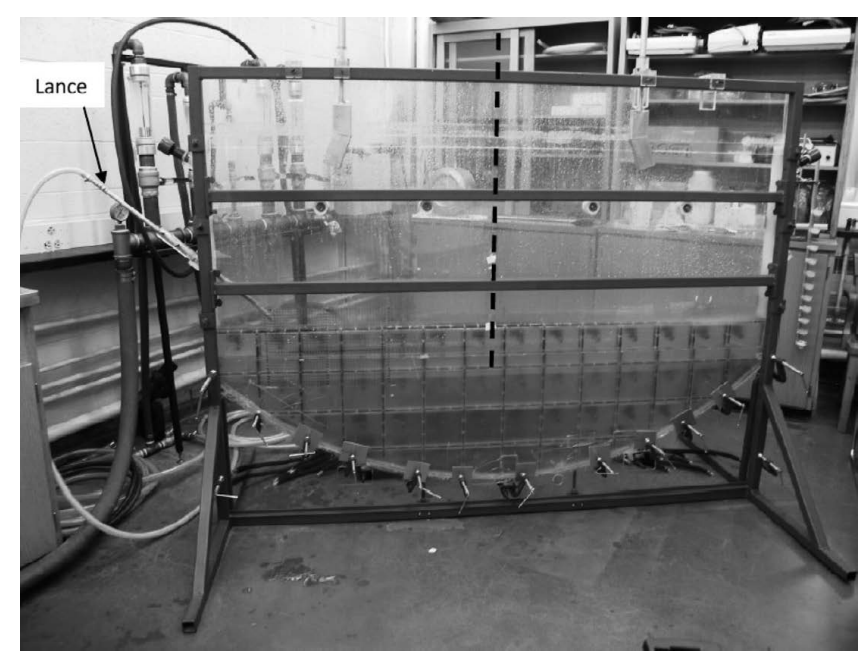

Fig. 1. The two dimensional thin slice model for the experimental study.

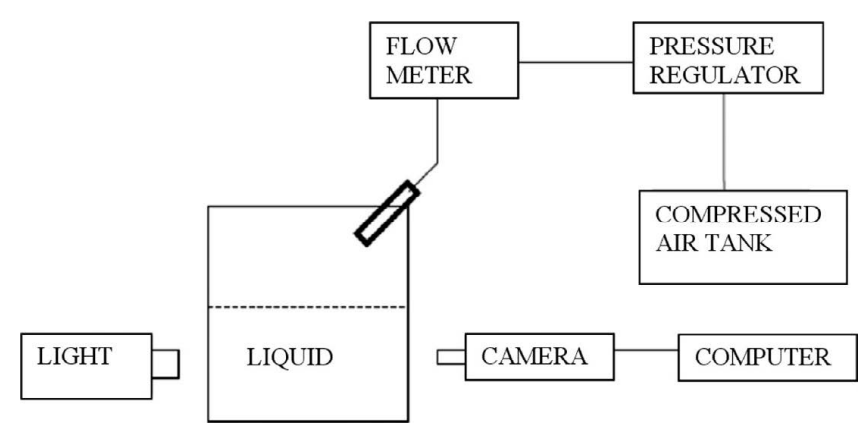

Fig. 2. Experimental Set-up. images were then used to measure the cavity depth and diameter with the help of the grid attached on the side wall of the water model. Splashing rates were measured by collecting the splashed liquid in eleven small plastic containers which were attached in an aluminium rod as shown in Fig. 3. The splashed liquid was collected at a distance of $750 \mathrm{~mm}$ (shown by dotted line in Fig. 1) from the jet impingement point. The length, width and height of each plastic container were $40 \mathrm{~mm}, 23 \mathrm{~mm}$ and $25 \mathrm{~mm}$ respectively. The plastic containers were numbered from 1 to 11 starting from the bottom (close to water surface). The gap between the bottom surface of first container and the water surface was $100 \mathrm{~mm}$. The gaps between containers are shown in the Fig. 3. After the impingement of gas jet and commencement of splashing, the aluminium rod with the buckets was inserted in the thin slice model, at the position shown by dotted line in Fig. 1, and then taken out after certain time. The time of splash collection was varied from 10 seconds (High Flow rate) to 3 minutes (Low flow rate). The total volume of water in each bucket was then measured by pouring them into a measuring flask and dividing by the time of splash collection to calculate the splashing rate in millilitres per second. Splashing rates were measured for three different lance angles $(35,40$ and 45 degrees from the vertical), five lance heights (65, $105,124,145$ and $165 \mathrm{~mm})$ and three flow rates $(0.43,0.57$, $\left.0.71 \mathrm{Nm}^{3} / \mathrm{min}\right)$. The flow rates were selected based on modified Froude Number similarity to model the Dofasco's full scale furnace. The details similarity analysis were presented elsewhere. ${ }^{16)}$ For each set of operating conditions (lance height, lance angle and flowrate), splashing rate was measured six times and the average was taken as the splashing rate for that particular operating condition. Only forward splashing rate was measured in the present study because of the thin slice nature of the model which is also the maximum splashing rate because in case of inclined jetting splashing rate is maximum in forward direction directly in front of the lance. The error in the measurement of splashed

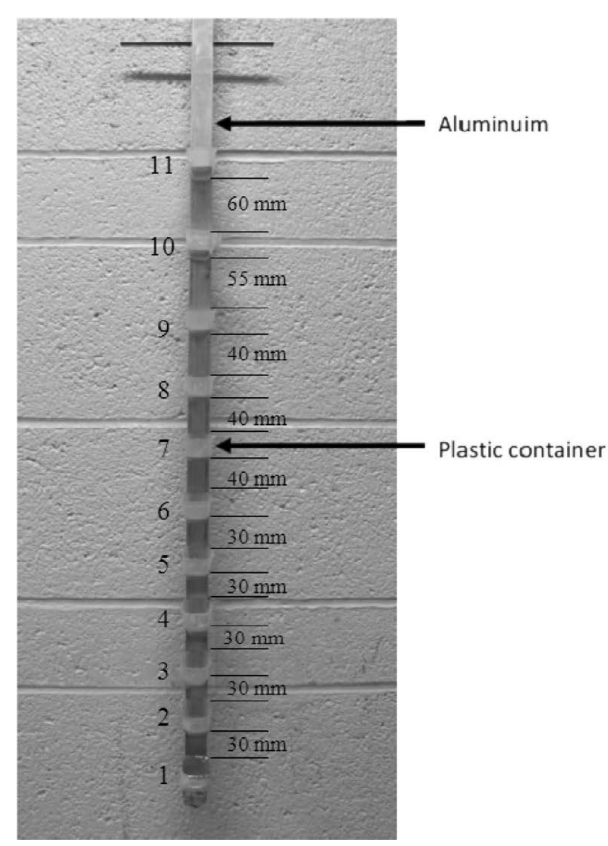

Fig. 3. Splash collector used in the study. 
liquid, penetration depth and time was $\pm 0.2 \mathrm{ml}, \pm 5 \mathrm{~mm}$ and $\pm 0.05 \mathrm{sec}$ respectively. Hence the total error in the measurement of splashing rate is $\pm 0.0043 \mathrm{ml} / \mathrm{sec}$ [See details of this calculation in Appendix]. A fine grid was used to measure the critical penetration depth; the accuracy of critical depth measurement was $\pm 1 \mathrm{~mm}$. The present experimental study under predicts the actual forward splashing rate because the droplets hitting the surface of the plastic bucket could not be collected in the plastic container for measurement.

\section{Results}

\subsection{Effect of Lance Gas Flow Rate}

Figure 4 shows that the higher the lance gas flow rate, the deeper the cavity which is expected because of the high dynamic pressure. McGee and Irons ${ }^{16)}$ showed that the depth of penetration is proportional to the square of flow rate. Figure 5 shows the splashing rate at different flow rates. As expected, splashing rates were higher at higher flow rates at all lance heights and angles. This is because at higher gas flow rates, the impact dynamic pressure as well as shear stress at the gas liquid interface is higher which in turn increases the droplet generation rate. But the slope of these curves was found to be different at different lance angles and lance heights. At $65 \mathrm{~mm}$ lance height, the splashing rate increased dramatically with lance angle compared with $165 \mathrm{~mm}$ lance height where the slope of the splashing curves did not vary significantly with lance angle. Also at 45 degree lance angle, splashing rate increased rapidly with flow rates compared to other lance angle at all lance heights. An explanation of these observations will be discussed in the next section.

\subsection{Effect of Lance Angle}

Figure 5 shows that at a constant flow rate and lance height, splashing rate increases with increasing lance angle from the vertical. This can be explained from the shape of the cavity formed during jetting. Figure 6 shows the shape of the cavity formed at two different operating conditions:

At 35 degree lance angle, deeper cavity was formed com-

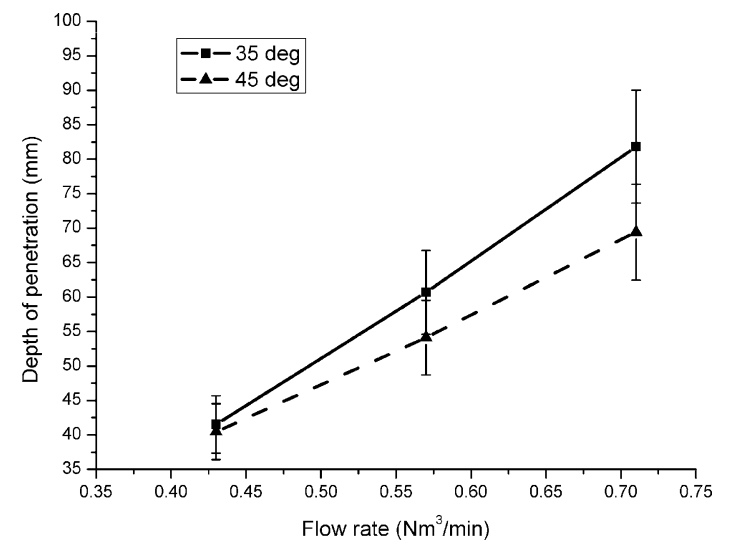

Fig. 4. Depth of penetration vs flow rate at lance angle of 35 degree and 45 degree at $0.105 \mathrm{~m}$ lance height. Data points are an average of 30 penetration depth measurements, the error bars are the standard deviation for the 30 measurements and were found to be approximately $10 \%$ of the average penetration depth. pared to 45 degree lance angle and the droplets that were generated from the edge of the cavity, recirculated into the cavity which in turn reduced the forward splashing rate. ${ }^{1)}$ This is known as the penetrating mode. ${ }^{20)}$ On the other hand, at 45 degree lance angle, the droplets that were generated from the edge of the cavity, moved forward and splashed on the wall of the furnace. This is known as the splashing mode $^{20)}$ of operation. With increasing lance angle from vertical, cavity shape changed from the penetrating mode to splashing mode which in turn increased the rate of wall splashing. Figure 5 also shows that at constant flow rate, increasing rate of splashing with lance angle is different at

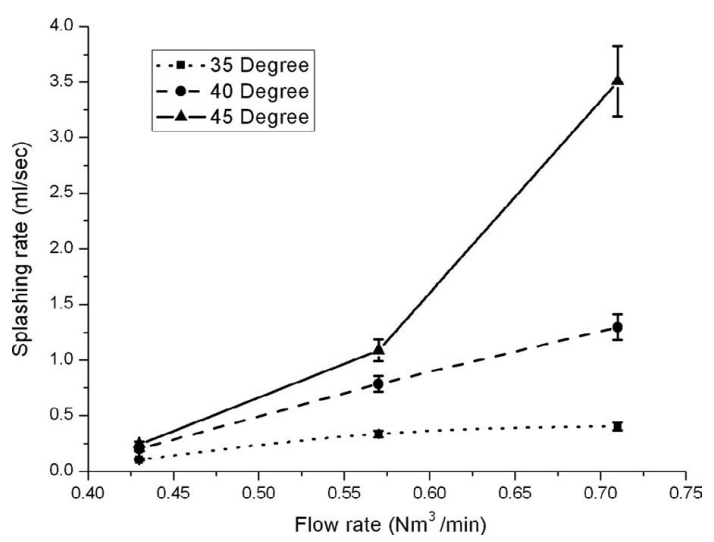

(a)

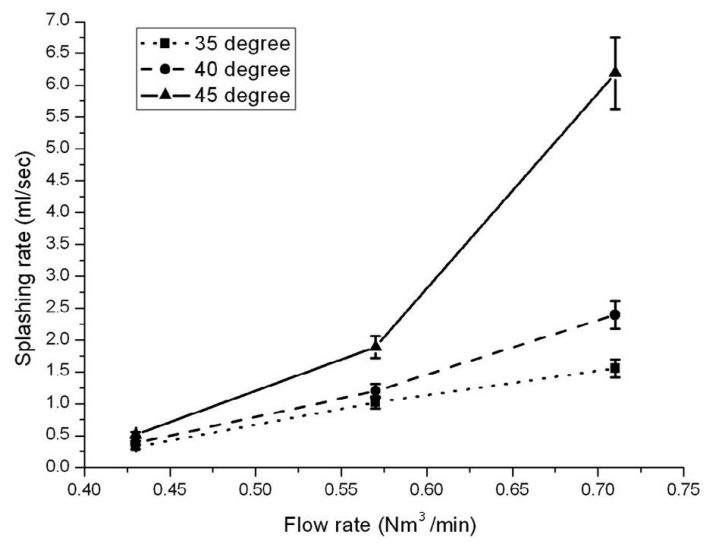

(b)

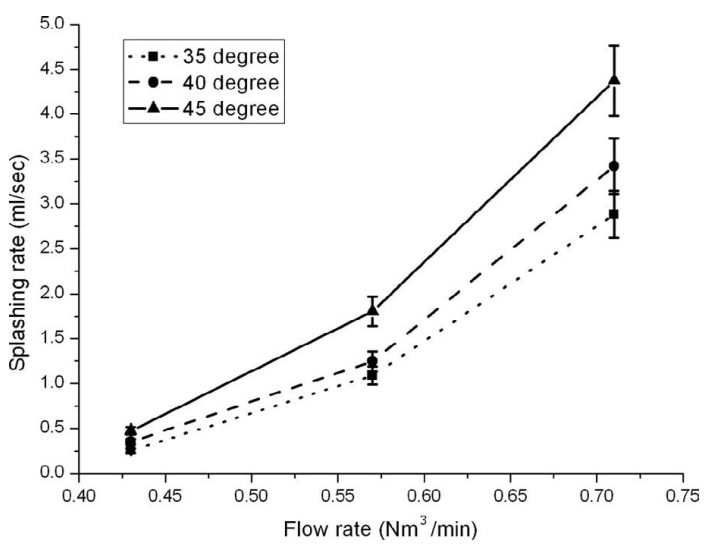

(c)

Fig. 5. Splashing rate vs flow rate at (a) $65 \mathrm{~mm}$ (b) $105 \mathrm{~mm}$ and (c) $165 \mathrm{~mm}$ lance heights. Data points are an average of 6 splashing rate measurements; the error bars are the standard deviation for the 6 measurements and were found to be approximately $9 \%$ of the average splashing rate. 


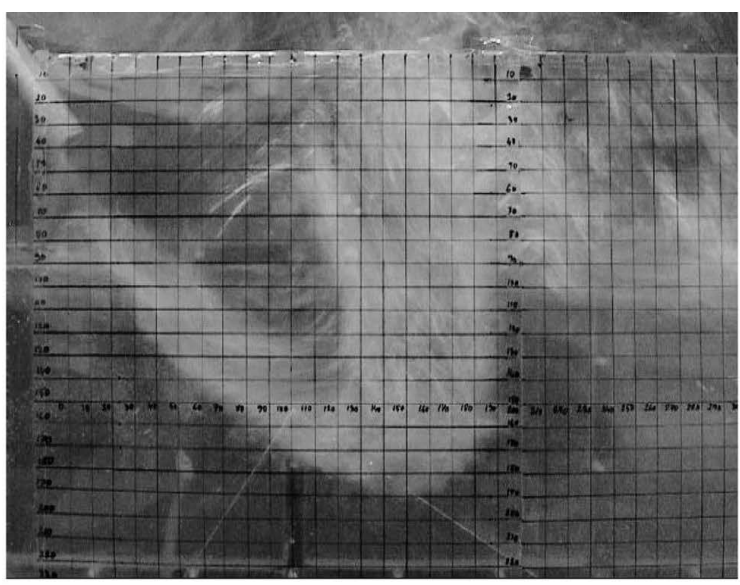

(a)

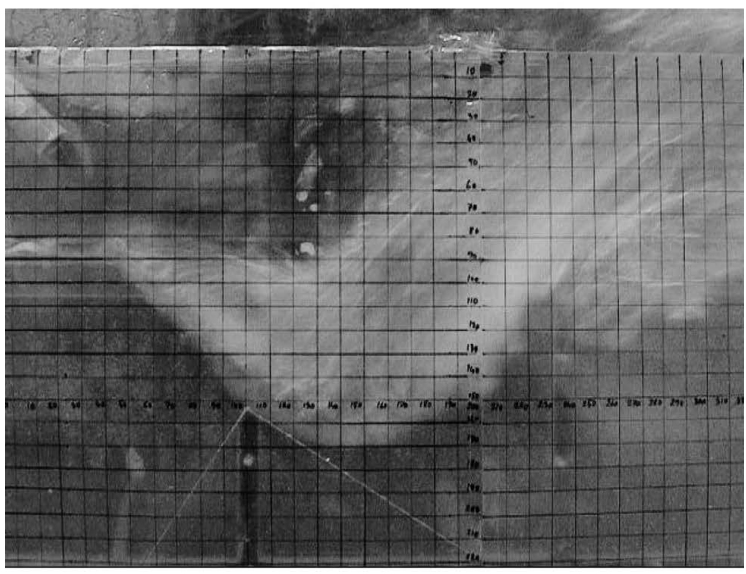

(b)

Fig. 6. Cavity formed at $65 \mathrm{~mm}$ lance height, $0.71 \mathrm{Nm}^{3} / \mathrm{min}$ flow rate and at a lance angle of (a) 35 degree and (b) 45 degree.

different lance heights. Figure 5 is modified and presented in Fig. 7 to show the effect of lance angle on splashing rate. In Fig. 7, rate of increase of forward splashing with lance angle is higher at $65 \mathrm{~mm}$ and $105 \mathrm{~mm}$ lance height compared with $165 \mathrm{~mm}$ lance height. As discussed earlier, at 65 $\mathrm{mm}$ lance height, the change in angle changed the impingement mode from penetrating to splashing which in turn increased the splashing rate. Also, the deflected gas velocity at the gas liquid interface after impingement was higher at the steeper lance angle which in turn increased the splashing rate because of high shear stress. This was also the case for $105 \mathrm{~mm}$ lance height. But at $165 \mathrm{~mm}$ lance height, the cavity was already in splashing mode at 35 degree lance angle. Droplets that were generating from the edge of the cavity were moving forward rather than recirculating inside the cavity. The change in lance angle from 35 degree to 45 degree increased the splashing rate only due to the increase in deflected gas velocity, as well as, the effect of the shear stress at the gas liquid interface, which has been described earlier. As a result, increasing rate of splashing (slope of the curves) is higher at $65 \mathrm{~mm}$ and $105 \mathrm{~mm}$ lance height compared to $165 \mathrm{~mm}$ lance height.

\subsection{Effect of Lance Height}

Figure 8 shows the change in splashing rate with lance height at different lance angles. At all lance angles, splashing rate increased with increasing lance height from the liq-

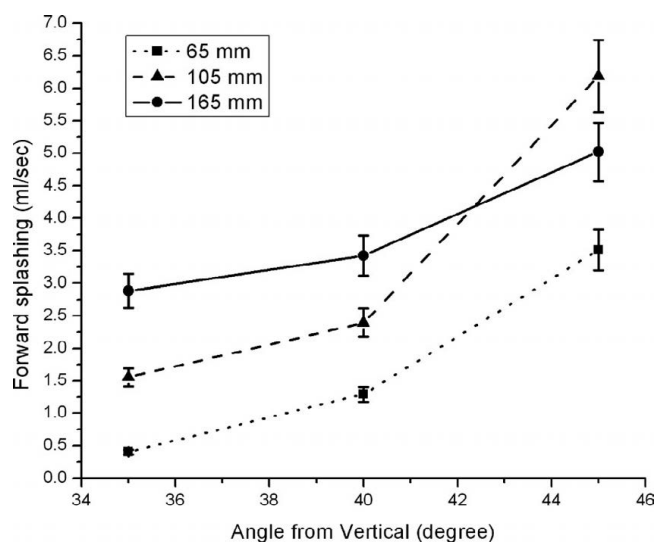

Fig. 7. Splashing vs lance angle at $0.71 \mathrm{Nm}^{3} / \mathrm{min}$ flow rate. Data points are an average of 6 splashing rate measurements; the error bars are the standard deviation for the 6 measurements and were found to be approximately $9 \%$ of the average splashing rate.

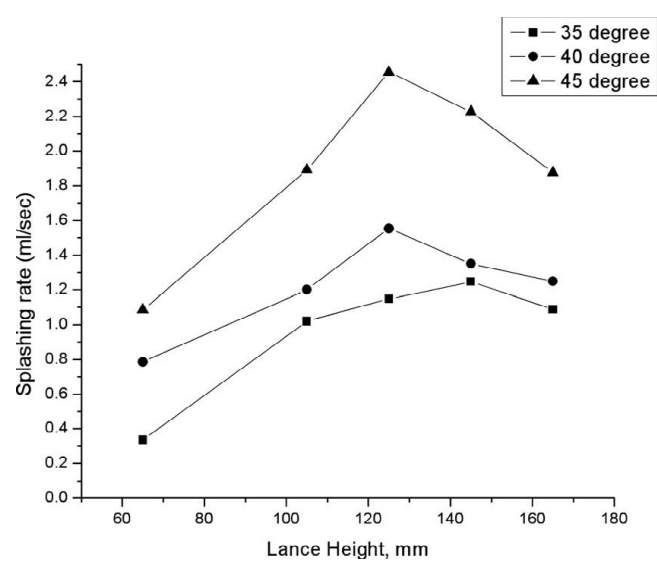

Fig. 8. Splashing rate as a function of lance height.

uid bath up to a critical distance and then started to decrease with further increase in lance height. When the nozzle was close to the surface, a very deep depression was formed in the liquid bath and the liquid droplets from the edge of the cavity recirculated into the cavity. With the increase of lance height, the cavity shape slowly converted from penetrating regime to splashing regime and the splashing rate increased. In other words, at higher lance height, the cavity was wider, providing large contact area for increased momentum transfer from gas to liquid. As a result more droplets were generated. When the critical lance height was reached, further increase in lance height decreased the momentum intensity at the surface and splashing rate was reduced. In case of top blowing similar trend was observed by the previous researchers. ${ }^{4,6,21)}$ Figure 8 also shows that the critical lance height at 35 degree lance angle was higher compared to 40 and 45 degree. This was expected because at 35 degree lance angle, deeper cavity was formed compared to 40 and 45 degree. As a result, change of cavity shape from the penetrating mode to splashing mode occurred at higher lance height.

\subsection{Splashing Distribution on the Wall}

The volume of splashed water in each plastic container was plotted against the container position to obtain the 
splash distribution on the wall for two different lance heights (Fig. 9). At lower lance height (65 mm), a higher proportion of liquid splashed towards the lower part the converter, close to the bath surface. Splashing rate on the upper part of the wall was very low compared to the lower part. Again the reason is the shape of the cavity formed at this particular operating condition. Also at lower lance height when the angle of inclination from the vertical was increased, the splashing rate also increased dramatically at the lower part of the wall due to transformation from penetrating to splashing mode. When the lance height was increased, more and more liquid splashed to the upper part

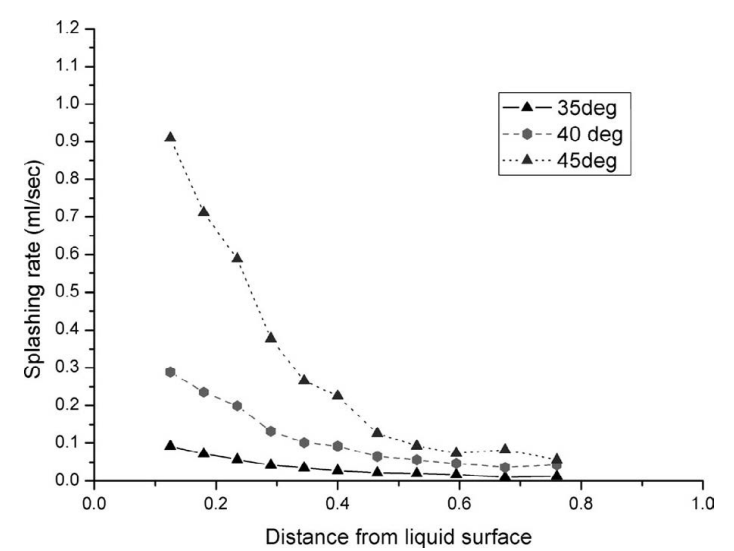

(a)

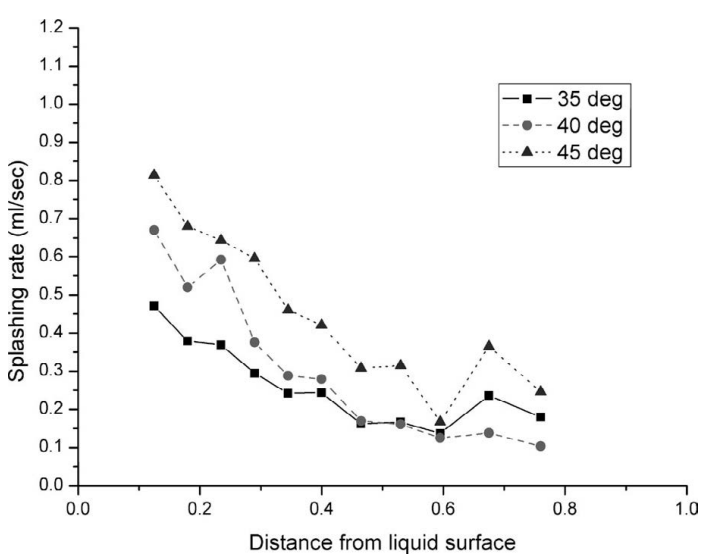

(b)

Fig. 9. Splash distributions on the wall at (a) $65 \mathrm{~mm}$ and (b) 165 $\mathrm{mm}$ lance heights. of the wall along with the lower part. At $165 \mathrm{~mm}$ lance height, as shown in Figs. 9(a) and 9(b), splashing rate on the upper part of the wall was higher than that of $65 \mathrm{~mm}$ lance height. This was because at $165 \mathrm{~mm}$ lance height, the cavity was wider compared to that at $65 \mathrm{~mm}$ lance height and hence, more of the generated droplets splashed to the upper part of the converter wall. From Fig. 9 it can be concluded that the wall splashing rate can be reduced by operating at low lance height (penetrating mode), but the lance angle should be selected carefully.

\section{Discussions}

\subsection{Dimensionless Relationship of Depth of Penetra- tion}

The interaction of a vertical gas jet with the liquid was first analysed theoretically by Banks and Chandrasekhara ${ }^{10)}$ using stagnation pressure analysis method. In the present study, their ${ }^{10)}$ stagnation pressure analysis has been modified for the inclined jetting case. Figure 10 shows the schematic of inclined jetting on a liquid surface:

The axial centreline velocity $U_{j}$ for a turbulent jet can be expressed as:

$$
U_{j}=\frac{U_{0} K_{2} D}{Y} \quad \text { when } Y>K_{2} D
$$

Where $U_{0}$ is the gas velocity at nozzle exit and $K_{2}$ is a constant. Neglecting the effect of surface tension, the vertical component of the gas dynamic pressure in the proximity of the stagnation point is balanced by the hydrostatic head:

$$
\frac{1}{2} \rho_{g} U_{j}^{2} \cos \theta=\rho_{l} P g
$$

Where $\rho_{g}$ and $\rho_{l}$ is the gas and liquid density respectively, $P$ is the depth of penetration and $\mathrm{g}$ is acceleration due to gravity. Combining Eqs. (1) and (2)

$$
\begin{aligned}
& \frac{1}{2} \rho_{g} U_{0}^{2} K_{2}^{2} \frac{D^{2}}{Y^{2}} \cos \theta=\rho_{l} P g \\
& \frac{\pi}{4} \rho_{g} U_{0}^{2} D^{2} \cos \theta=\frac{\pi}{2 K_{2}^{2}} \rho_{l} P g Y^{2} \\
& \frac{M \cos \theta}{\rho_{l} g P}=\frac{\pi}{2 K_{2}^{2}} Y^{2} \quad\left[M=\frac{\pi}{4} \rho_{g} U_{0}^{2} D^{2}\right]
\end{aligned}
$$

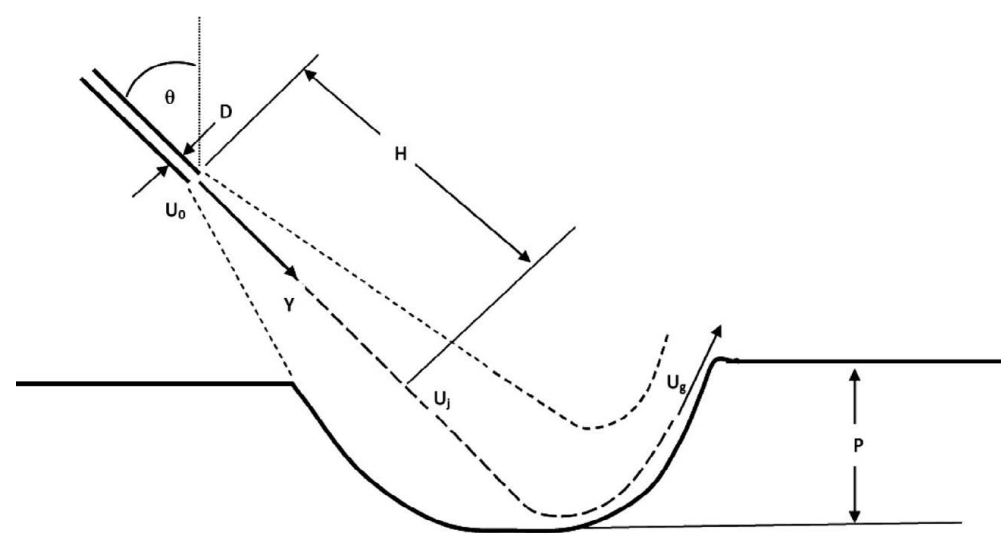

Fig. 10. Schematic of inclined jetting. 

get,

Now using $Y=H+\frac{P}{\cos \theta}$ in Eq. (3) and rearranging we
et,

$$
\frac{M \cos \theta}{\rho_{l} g H^{3}}=\frac{\pi}{2 K_{2}^{2}}\left(\frac{P}{H}\right)\left(\frac{P}{H \cos \theta}+1\right)^{2}
$$

Figure 11 shows the plot of dimensionless jet momentum vs the dimensionless cavity depth. The plot shows a straight line and the slope of this straight line is 34.92 which is equal to $\frac{2 K_{2}^{2}}{\pi}$. Hence, the value of $K_{2}$ in the present study is calculated as 7.4 , which is in the range of the $K_{2}$ values (6.4 to 7.9) calculated by the previous researchers. ${ }^{3,10,12,21)}$

\subsection{Critical Depth of Penetration}

In the present study, the critical depth of penetration of water at different lance angle was measured at constant lance height. Critical depth of penetration means the depth at which the droplet generation starts. Chatterjee and Bradshaw $^{3)}$ proposed an equation to calculate the critical depth of penetration of different liquids for top jetting. They concluded that critical depth of penetration depends only on liquid properties and the influence of lance height is negligible. Shrivastava et $a l^{22}{ }^{22}$ found that the critical depth of penetration for the onset of splashing decreases with the increasing lance angle from the vertical. Similar observation was made in the present study. Although the penetration depth deceases linearly with lance angle, ${ }^{16)}$ Fig. 12 shows that the critical depth of penetration does not decrease linearly with lance angle. The critical depth of penetration was found to have a parabolic relationship with the angle and can be expressed as:

$$
P_{c}=0.0151 \cos ^{2.0079} \theta \approx P_{\text {ctop }} \cos ^{2} \theta
$$

Using the above equation, the critical depth of penetration at different lance angle can be determined if the critical depth for top jetting case is known. At zero degree (top jetting) lance angle, critical depth of penetration for water becomes $0.0151 \mathrm{~m}$ which is close to the value of $0.0154 \mathrm{~m}$ for top jetting case. ${ }^{19)}$

$\mathrm{Li}$ and Harris ${ }^{19)}$ derived an equation for calculating the critical tangential gas velocity at the onset of splashing based on Kelvin-Helmholtz instability:

$$
\frac{1}{2} \rho_{g} U_{g}^{2}=\sqrt{\sigma g \rho_{l}}
$$

Where $U_{g}$ is the critical tangential gas velocity and is shown in Fig. 10. They have related the critical gas velocity $U_{g}$ with the free turbulent jet axial velocity $U_{j}$, using the following equation

$$
U_{g}=\eta U_{j}
$$

Where $\eta$ defines the fraction of the jet velocity at the impingement point that is converted to the tangential velocity across the gas-liquid interface. From the previous works with top jetting, the value of $\eta$ has been found to be $0.42 .{ }^{19)}$ It is apparent from Fig. 10 that the value of $\eta$ will depend on the angle of inclination. At a higher inclination angle from the vertical, the fraction of jet velocity converted to tangential velocity increases. Now substitut-

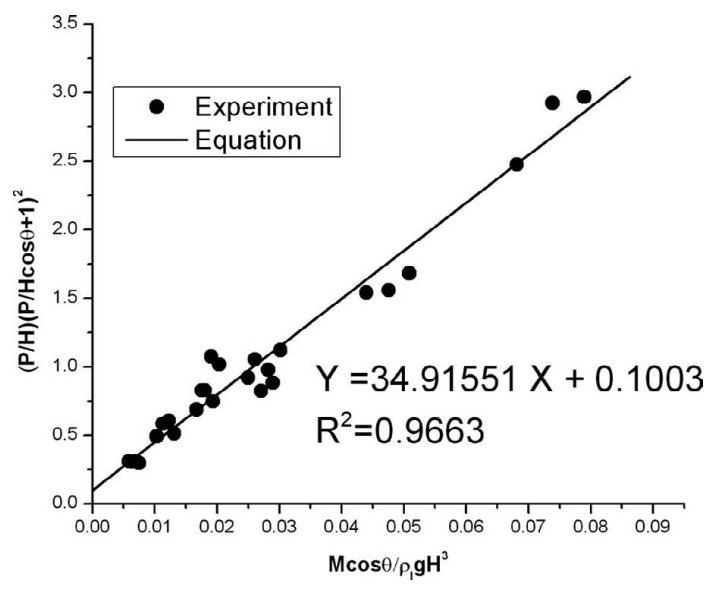

Fig. 11. Dimensionless jet momentum vs cavity depth.

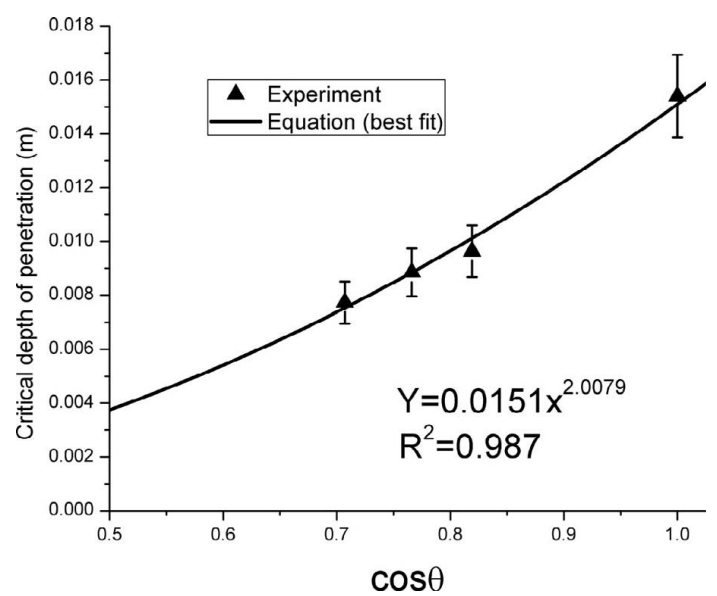

Fig. 12. Variation of critical depth of penetration with angle of inclination.

ing $U_{g}$ in Eq. (5) using Eq. (6),

$$
\frac{1}{2} \rho_{g} U_{j}^{2}=\frac{1}{\eta^{2}} \sqrt{\sigma g \rho_{l}}
$$

Where $\sigma$ is the surface tension of the liquid. Considering the balance of vertical component of gas dynamic pressure and hydrostatic head at critical depth of penetration:

$$
\frac{1}{2} \rho_{g} U_{j}^{2} \cos \theta=\rho_{l} P_{c} g
$$

Combining Eqs. (7) and (8),

$$
P_{c}=\frac{\cos \theta}{\eta^{2}} \sqrt{\frac{\sigma}{\rho_{l} g}}
$$

Equation (8) clearly shows that the critical depth of penetration depends on both angle and $\eta$ value. That is why the critical depth of penetration is not a linear function of angle. Using the experimentally determined critical depth of penetration, the value of $\eta$ can be calculated at different lance angle using Eq. (9). Figure 13 shows the variation of $\eta$ with lance angle. From the experimental data, a relationship can be obtained between the value of $\eta$ and lance angle:

$$
\eta=\frac{0.4231}{\cos ^{0.523} \theta} \approx \frac{0.4231}{\sqrt{\cos \theta}}
$$




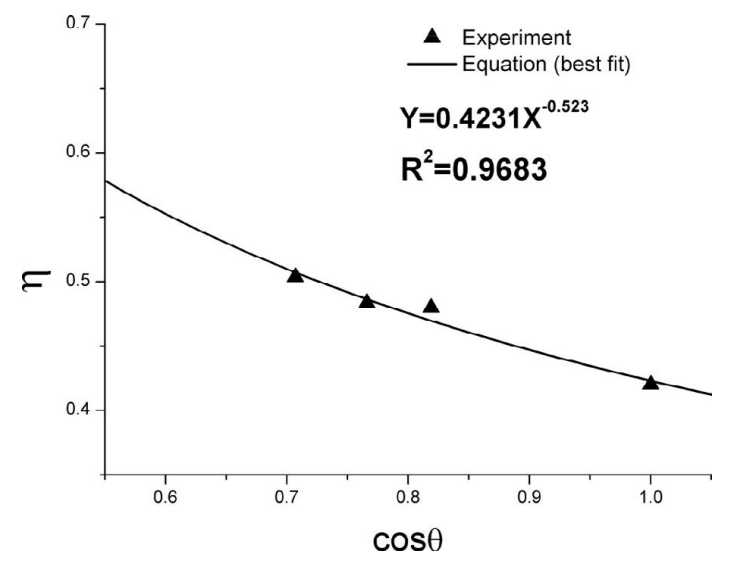

Fig. 13. Variation of $\eta$ with lance angle.

Hence, the value of $\eta$ at different lance angle can be calculated by dividing the top jetting value of $\eta$ by the factor $\sqrt{\cos \theta}$.

\subsection{Effect of Lance Angle on Blowing Number}

In order to quantify the droplet generation rate, Subagyo et $a{ }^{8}{ }^{8)}$ defined a dimensionless blowing number $\left(N_{B}\right)$ by rearranging Eq. (7):

$$
N_{B}=\frac{\eta^{2} \rho_{g} U_{j}^{2}}{2 \sqrt{\sigma g \rho_{l}}}
$$

Blowing number is an estimate of how many times the critical Kelvin-Helmholtz interface instability has been exceeded. Droplet generation starts when the blowing number is equal to one. Calculating the value of $\eta$ using Eq. (9), the critical impact velocities $\left(U_{j}\right)$ at the onset of splashing at different lance angles were calculated using Eq. (10) assuming Blowing number equal to one and are presented at Table 1.

Table 1 shows that in case of top jetting, the critical velocity for the onset of splashing is $15.74 \mathrm{~m} / \mathrm{s}$ which was also shown by previous researchers. ${ }^{20)}$ Table 1 also shows that the higher the angle of inclination from the vertical, the lower the critical impact velocity at the onset of splashing. In other words, Blowing number at the gas-liquid interface reaches unity at lower impact velocity because of higher $\eta$ values. If the lance angle is greater than 79 degree, the value of $\eta$ exceeds 1 according to Eq. (10) which is theoretically impossible. Also when the lance angle becomes 90 degree, the critical dynamic pressure becomes zero. But there will be some splashing even if the gas jet flows parallel to the interface. So Eqs. (8)-(10) should not be used for lance angles higher than 79 degree from the vertical. In EAF steelmaking, normally the lance angle does not exceed 50 degree from the vertical. Hence, Eqs. (8)-(10) can be used for normal EAF steelmaking range. But further experimental study is required to develop a more rigorous equation for calculating $\eta$ value at different lance angles.

Subagyo et $a l .{ }^{8)}$ reported that the droplet generation rate increases with Blowing number. The present study shows that at constant lance height and flow rate, the blowing number on the jet-liquid interface increases with increasing lance angle from the vertical due to an increase in $\eta$ value. Figure 14 shows the variation of Blowing number with
Table 1. Critical impact velocities at different lance angles.

\begin{tabular}{ccc}
\hline Angle, $\theta$ & $\eta$ & $\begin{array}{c}\text { Critical impact velocity } \\
U_{j}(\mathrm{~m} / \mathrm{s})\end{array}$ \\
\hline 0 & 0.4231 & 15.74 \\
5 & 0.4240 & 15.71 \\
10 & 0.4264 & 15.62 \\
15 & 0.4305 & 15.47 \\
20 & 0.4365 & 15.26 \\
25 & 0.4444 & 14.98 \\
30 & 0.4546 & 14.65 \\
35 & 0.4675 & 14.24 \\
40 & 0.4834 & 13.78 \\
45 & 0.5031 & 13.23 \\
50 & 0.5277 & 12.62 \\
\hline
\end{tabular}

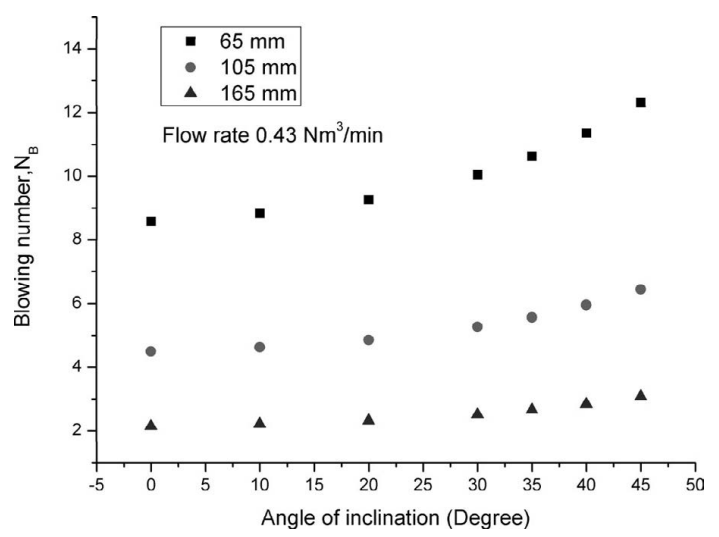

Fig. 14. Variation of Blowing number with lance angle.

lance angle at three different lance heights and $0.43 \mathrm{Nm}^{3}$ / min flow rate. The velocity of the gas jet at the interface were calculated by using the following expression: ${ }^{4)}$

$$
U_{j}=U_{0} \frac{0.97}{\frac{0.14 \times H}{D}+0.29}
$$

The axial velocity at a distance of less than five nozzle exit diameters was assumed as equal to the nozzle exit velocity which is a reasonable assumption because it was reported that the nozzle exit velocity remain constant for three to eight nozzle exit diameter. ${ }^{23)}$ It was discussed in the previous section that the wall splashing rate increases with increasing lance angle. But an increase in blowing number does not always mean an increase in wall splashing rate although it increases the droplet generation rate. The Blowing number during inclined jetting depends on both flow rate and lance angle. If the flow rate is high but the cavity is in penetrating mode, the wall splashing rate may be lower than those operating at low flow rate and in splashing mode. Figure 15(a) shows that at $0.57 \mathrm{Nm}^{3} / \mathrm{min}$ flow rate and 45 degree lance angle, the Blowing number is $\mathrm{N}_{\mathrm{b}}=22$ which is lower than the Blowing number $\left(\mathrm{N}_{\mathrm{b}}=29\right)$ at $0.71 \mathrm{Nm}^{3} / \mathrm{min}$ flow rate and 35 degree lance angle. But the wall splashing rate for the former condition is higher than the later one. The reason behind this is the shape of the cavity. At 0.57 


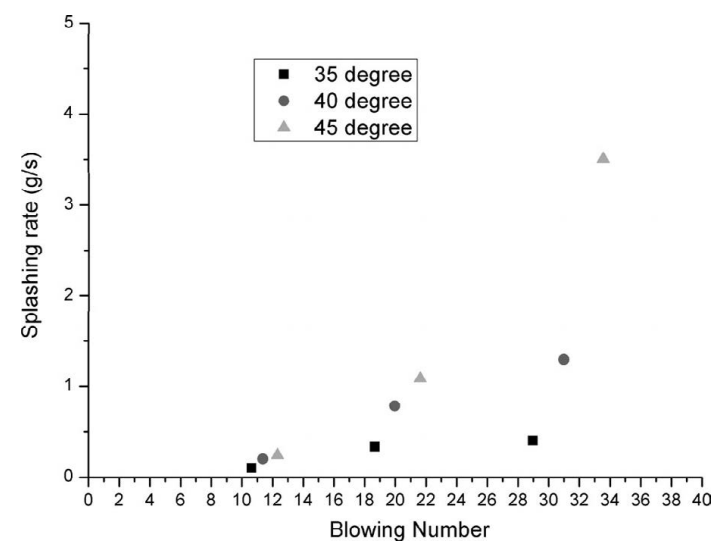

(a)

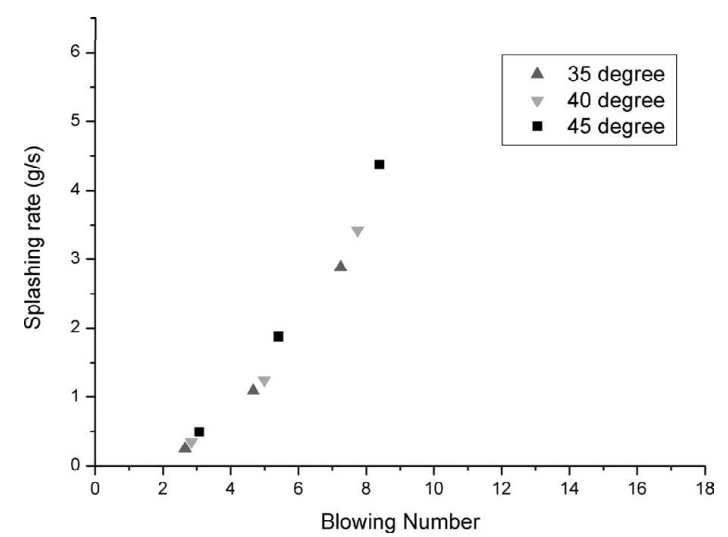

(b)

Fig. 15. Wall splashing rate at different blowing number at (a) 65 $\mathrm{mm}$ and (b) $165 \mathrm{~mm}$ lance height.

$\mathrm{Nm}^{3} /$ min flow rate and 45 degree lance angle the cavity is operating in splashing mode whereas at $0.71 \mathrm{Nm}^{3} /$ min flow rate and 35 degree lance the cavity is operating in penetrating regime. But if there is no regime change occurs, an increase in Blowing number will always increase the wall splashing rate as shown in Fig. 15(b), where the cavity is operating in splashing regime. Hence, it is very difficult to come up with an empirical equation for calculating the wall splashing rate at different Blowing number because of the regime change.

\subsection{Modelling of Full-scale Furnace}

Achieving complete similarity of a complex system like EAF steelmaking process is difficult. In the present study, a different approach was used to model the gas jet impinging phenomenon in the real process using the room temperature water model. But no effort was made to model the magnetic force resulting from the electrode. In order to maintain the dynamic similarity between the real process and water modelling, previous researchers have used the modified Froude number: ${ }^{16)}$

$$
F r_{m}=\frac{\rho_{g} U_{0}^{2}}{\rho_{l} g D}
$$

Where $U_{0}$ is the gas jet velocity at the nozzle exit. Using the modified Froude number, the velocity of the gas jet at the exit of the nozzle for the water model was calculated in the present study. Then the Blowing number similarity was maintained at the liquid surface because it was reported by
Table 2. Dimensional analysis of the full-scale furnace.

\begin{tabular}{ccc}
\hline & One Steel & One-fifth scale model \\
\hline Liquid/gas & Steel/Oxygen & Water/air \\
Liquid density & $7000 \mathrm{~kg} / \mathrm{m}^{3}$ & $1000 \mathrm{~kg} / \mathrm{m}^{3}$ \\
Gas density at nozzle exit & $2.3 \mathrm{~kg} / \mathrm{m}^{3}$ & $1.18 \mathrm{~kg} / \mathrm{m}^{3}$ \\
Volumetric flow rate & $40 \mathrm{Nm}^{3} / \mathrm{min}$ & $0.1984 \mathrm{Nm} / \mathrm{min}^{3}$ \\
Lance diameter & $31.75 \mathrm{~mm}$ & $6 \mathrm{~mm}$ \\
Velocity at nozzle exit & $490 \mathrm{~m} / \mathrm{s}$ & $111 \mathrm{~m} / \mathrm{s}$ \\
Modified Froude number & 249.166 & 249.166 \\
Lance height & $1.5 \mathrm{~m}$ & $0.046 \mathrm{~m}$ \\
Velocity on liquid surface & $79 \mathrm{~m} / \mathrm{s}$ & $79 \mathrm{~m} / \mathrm{s}$ \\
Blowing number & 35.63 & 35.63 \\
Lance angle & $45 \mathrm{degree}$ & $45 \mathrm{degree}$ \\
\hline
\end{tabular}

Subagyo et al. ${ }^{8)}$ that similar blowing number at the jet-liquid surface results in similar droplet generation rate. The present authors developed a CFD model to calculate the supersonic jet velocity characteristics at steelmaking temperature. ${ }^{24}$ Using this model and Eq. (11) the Blowing number at the liquid surface inside the real furnace was calculated for a particular lance angle. Then from the blowing number similarity the velocity of the gas jet on the water surface $\left(U_{j}\right)$ required to maintain the similar blowing number in water model was calculated. After that the lance height $(\mathrm{H}$ in Fig. $10)$ required to decay from nozzle exit velocity $\left(U_{0}\right)$ to the water surface velocity $\left(U_{j}\right)$, was determined using Eq. (12). ${ }^{4}$ Then the operating condition in the experiment was fixed to that particular gas velocity and lance height and the splashing rates were measured. The dimensional analysis for the modelling of real furnace of OneSteel operating in Laverton is shown in Table 2:

The splashed liquids were collected at 65 nozzle exit diameter $(65 \times 6=390 \mathrm{~mm})$ from the jet impingement point in the water model and the splashing rates were calculated. The splashing rate at 45 degree lance angle was calculated as $0.27 \mathrm{ml} / \mathrm{s}$ which is equal to $0.27 \mathrm{~g} / \mathrm{s}$ for water. As the blowing number similarity were maintained here, it can be said that the splashing rates will be the same in case of real furnace assuming only steel as liquid with no slag on the surface. In case of real furnace the forward splashing rate of steel are expected to be $1.91 \mathrm{~g} / \mathrm{s}$ (weight of splashed steel). However, industrial trials are required to confirm this prediction.

The present experimental study was performed using a thin slice model to get a better view of the cavity shape. The depth of penetration in the 3D model for a particular jet velocity would be slightly lower than that in thin slice model because jet spreading in two direction only in thin slice model. Hence, the value of $K_{2}$ in Eq. (4) would be slightly different in case of 3D model. Thin slice nature of the model may have some effect on the critical penetration depth measurement also. But the present experimental study gives a better understanding of the splashing phenomenon in the case of inclined jetting.

In the present study, the no-slag condition was considered. We assumed that the impinging gas jet pushes the slag layer away from the impingement zone and exposes the 
liquid metal to the high speed gas jet. ${ }^{12)}$ Previous studies ${ }^{1,8)}$ suggested that the metal droplets are generated from the gasmetal interface and then the droplets may splash outside or recirculate inside the cavity depending on the impingement mode. If a slag layer is present on top of the liquid metal, some metal droplets with low kinetic energy will end up in the slag layer and reduce the wall splashing rate. Previous studies $^{16,17,25)}$ showed that thicker, more viscous and foamy slags result in less splashing. In conclusion, it can be said that the splashing rate would be different if a second liquid is used to simulate slag and further work is needed to include the effect of slag in the present model.

\section{Conclusions}

Water modelling experiments have been carried out to understand the effect different operating parameters on wall splashing rate in EAF steelmaking. The following conclusions can be drawn from this study:

(1) The forward splashing rate increases with the increase of lance angle and flow rate.

(2) The splashing rate is not a monotonous function of lance height. Splashing rate increases with lance height up to a critical distance and after that splashing rate decreases with the increase of lance height. The trend is similar at all lance angles from 35 to 45 degree.

(3) The splashing rate is lowest when operating in penetrating regime.

(4) The splashing rate is highest at the lower region of the wall, close to liquid surface.

(5) The use of higher lance height (less than the critical lance height) increases the overall splashing rate and more liquid splashes on the upper part of the wall compared to low lance height. At low lance height, splashing rate is reduced and is concentrated on the lower part of the wall.

(6) For inclined jetting, droplet generation starts at shallower critical depth of penetration and at lower impact velocity. Critical depth of penetration is proportional to the square of the cosine of lance angle.

(7) The Blowing number at the jet-liquid interface increases with the increase of lance angle from the vertical.

From the present experimental investigation, wall splashing rate can be reduced by placing the nozzle close to the surface and operating in penetrating regime. But there is a chance of nozzle wear due to the back splashing of liquid droplets on the nozzle. This can be avoided by the introduction of coherent jet nozzle ${ }^{26)}$ in the EAF furnace. A coherent jet gives the advantage of installing the nozzle at higher lance height because it can maintain the higher impact pressure on the bath surface to produce the penetrating regime even at higher lance height. But the angle of inclination should be carefully selected because it is shown in the present study that slight change in angle increases the splashing rate dramatically because of change in impinging mode from penetrating to splashing.

\section{Nomenclature}

$D$ : Nozzle exit diameter $(\mathrm{m})$

$\mathrm{Fr}_{m}$ : Froude number (-) g: Gravitational acceleration $\left(\mathrm{m} / \mathrm{s}^{2}\right)$

$H$ : Axial distance $(\mathrm{m})$

$K_{2}$ : Jet constant (-)

$M$ : Momentum of the jet $(\mathrm{N})$

$N_{B}$ : Blowing number (-)

$P$ : Depth of penetration (m)

$P_{c}$ : Critical penetration depth $(\mathrm{m})$

$U_{0}$ : Nozzle exit velocity $(\mathrm{m} / \mathrm{s})$

$U_{g}$ : Critical tangential velocity $(\mathrm{m} / \mathrm{s})$

$U_{j}$ : Jet centreline velocity $(\mathrm{m} / \mathrm{s})$

$\theta$ : Angle of lance from the vertical (Degree)

$\rho_{g}:$ Density of gas $\left(\mathrm{kg} / \mathrm{m}^{3}\right)$

$\rho_{l}$ : Density of liquid $\left(\mathrm{kg} / \mathrm{m}^{3}\right)$

$\sigma:$ Surface tension of liquid $(\mathrm{N} / \mathrm{m})$

\section{REFERENCES}

1) K. D. Peaslee and D. G. C. Robertson: EPD Cong. Proc., TMS, Pennsylvania, (1994), 1129.

2) N. Standish and Q. L. He: ISIJ Int., 29 (1989), 455.

3) A. Chatterjee and B. A. C.: J. Iron Steel Inst., 210 (1972), 179.

4) Q. L. He and N. Standish: ISIJ Int., 30 (1990), 305.

5) G. Turner and S. Jahanshahi: Trans. Iron Steel Inst. Jpn., 27 (1987), 734.

6) T. M. J. Fabritius, J. M. Luomala, E. O. Virtanen, H. Tenkku, T. L. J. Fabritius, T. P. Siivola and J. J. Harkki: ISIJ Int., 42 (2002), 861.

7) J. M. Luomala, E. O. Virtanen, T. P. Sivola, T. M. J. Fabritius and J. J. Harkki: Steel Res., 73 (2002), 9.

8) Subagyo, G. A. Brooks, K. S. Coley and G. A. Irons: ISIJ Int., 43 (2003), 983.

9) A. K. Garg and K. D. Peaslee: Iron Steelmaker, 25 (1998), 57.

10) R. B. Banks and D. V. Chandrasekhara: J. Fluid Mech., 15 (1963), 13.

11) F. R. Cheslak, J. A. Nicholls and M. Sichel: J. Fluid Mech., 36 (1969), 55

12) F. Qian, R. Mutharasan and B. Farouk: Metall. Mater. Trans. B, 27 (1996), 911.

13) World Steel Association, www.steeluniversity.org, (2011).

14) R. D. Collins and H. Lubanska: Br. J. Appl Phys., 5 (1954), 22.

15) C. Holden and A. Hogg: J. Iron Steel Inst., (1960), 318.

16) P. McGee and G. A. Irons: Iron Steelmaker, 29 (2002), 59.

17) K. D. Peaslee and D. G. C. Robertson: Steelmaking Conf. Proc., Iron \& Steel Soc of AIME, Warrendale, PA, (1994).

18) M. Lee, V. Whitney and N. Molloy: Scand. J. Metall., 30 (2001), 330.

19) R. Li and R. L. Harris: Pyrometallurgy 95 conf. Proc., The Institute of Mining and Metallurgy, London, (1995).

20) N. A. Molloy: J. Iron Steel Inst., 206 (1970), 943.

21) H. Y. Hwang and G. A. Irons: AISTech 2009, AIST, Warrendale, PA, (2009). 769.

22) U. S. Shrivastava, A. K. Chakraborty and S. L. Malhotra: Indian J. Technol., 14 (1976), 611.

23) B. Deo and R. Boom: Fundamentals of Steelmaking Metallurgy, Prentice Hall, Hertfordshire, (1993), 28.

24) M. Alam, J. Naser and G. A. Brooks: Metall Trans B, 41 (2010), 636.

25) J. M. Luomala, T. L. J. Fabritius, E. O. Virtanen, T. P. Siivola and J. J. Harkki: ISIJ Int., 42 (2002), 944.

26) J. E. Anderson, N. Y. Somers, D. R. Farrenkopf and C. Bethel: US Patent 5823762, (1998).

\section{Appendix}

\section{Error in the calculation $p=\frac{a}{b}$}

If $a$ is splashed liquid and $b$ is the time of splash collection then the splashing rate $p$ can be calculated using $p=\frac{a}{b}$. The error in the calculation of $p$ is:

$$
\frac{\delta p}{p}=\frac{\delta a}{a}+\frac{\delta b}{b}
$$

Where $\delta a, \delta b$ and $\delta p$ are the error in $a, b$ and $p$ respectively. 